\title{
Indirect costs associated with ulcerative colitis: a systematic literature review of real- world data
}

\author{
Joelle Constantin ${ }^{1^{*}}$ D, Petar Atanasov ${ }^{1}$, Daniel Wirth ${ }^{2}$ and Andras Borsi ${ }^{3}$
}

\begin{abstract}
Background: The economic burden of ulcerative colitis (UC), specifically related to indirect costs, is not extensively documented. Understanding and quantifying it is required by health care decision makers.

Aim: To assess the impact of indirect costs of UC in observation studies.

Method: A systematic literature search was conducted in MEDLINE ${ }^{\oplus}$, Embase ${ }^{\circledast}$ and Cochrane Library to capture all relevant publications reporting outcomes on absenteeism, presenteeism and productivity losses in moderate to severe UC. Eligibility criteria for inclusion into the review were established using a predefined PICOS scheme. All costs were adjusted to 2017 currency values (USD dollars, \$).

Results: In total, 18 studies reporting data on indirect costs were included in the analysis. Absenteeism costs were classified into three categories: sick leave, short-term and long-term disability. Most of the studies captured absenteeism costs related specifically to sick leave, which was experienced on average by 10 to $24 \%$ patients with UC. Only three studies captured presenteeism costs, as these are difficult to measure, however costs ranged from 1602 \$ to 2947 \$ per patient year. The proportion of indirect costs accounted for 35\% of total UC costs (Total UC costs were defined as the sum of healthcare costs, productivity costs and out-of-pocket costs).
\end{abstract}

Discussion: A limited number of studies were identified describing the indirect costs in patients with moderate to severe UC. Insufficient data on different components of costs allowed a limited analysis on the impact of indirect costs in patients with UC. Further studies are needed to gain an understanding of the influence of UC on patients' functional abilities.

Keywords: Inflammatory bowel disease, Ulcerative colitis, Indirect costs, Productivity loss, Financial burden, Real world evidence, Systematic literature review

\section{Background}

Ulcerative colitis (UC) is a chronic disease that is characterized by diffuse mucosal inflammation limited to the colon $[1,2]$. In about $95 \%$ of cases, UC affects the rectum and may extend to involve part or all of the large intestine. The clinical course of the disease is marked by episodes of exacerbations and remissions, occurring spontaneously or in response to treatment changes [3]. In spite of recent advances in therapy, the clinical burden and morbidity associated with UC remain high and

\footnotetext{
* Correspondence: joelle.constantin@amaris.com

${ }^{1}$ Amaris, Barcelona, Spain

Full list of author information is available at the end of the article
}

may result in social and psychological sequelae if poorly controlled [4].

The management of UC has changed with the approval of new biological therapies such as infliximab, which was approved by the FDA (2005) and by the EMA (2006) for the treatment of moderate to severe UC $[5,6]$.

Apart from the clinical repercussions associated with this disease, UC also has a societal burden on patients and their caregivers. On a global scale, this disorder accounts for a quarter million physician visits, 30,000 hospitalizations, and more than a million workdays missed annually [7]. The direct medical costs alone exceed 4 billion dollars (USD) annually and are driven mainly by hospitalization events [7]. The economic burden of UC,

(c) The Author(s). 2019 Open Access This article is distributed under the terms of the Creative Commons Attribution 4.0 International License (http://creativecommons.org/licenses/by/4.0/), which permits unrestricted use, distribution, and 
specifically related to indirect costs, has not been extensively documented. As indirect costs account for a significant percentage of total UC costs, understanding and quantifying the economic burden of UC is required by health care systems to control and avoid costs associated to productivity losses in a societal perspective $[7,8]$.

vConclusions drawn from clinical trials are not always sufficient for decision makers, as they assess the value of a specific drug in a controlled setting. However, real word studies that collect data beyond Phase III controlled trials (i.e. under real life practice) allow decision makers to better manage and understand uncertainties, specifically related to epidemiology, compliance, adherence and cost insights [9]. The aim of this systematic literature review (SLR) was to assess the impact of indirect costs of UC, especially related to surgery and to the use of biologic therapies in real world.

\section{Materials and methods Indirect costs}

As previously defined in the publication by Kawalec et al. [10] indirect costs (or productivity losses) are the labor earnings that are forgone as a result of an adverse health outcome. A decrease in productivity can result in illness, early death, side effects, or even time spent receiving treatment. Indirect costs can be categorized into three major components: (1) absence from paid work including sick leave, early retirement and reduced employment or unemployment (absenteeism), (2) reduced productivity of paid work (presenteeism), and (3) reduced opportunities for unpaid activities (loss of leisure) [11].

\section{Literature search}

This review was conducted to identify studies that report indirect costs in ulcerative colitis. The protocol for this review was not registered.

The electronic databases Embase ${ }^{\circ}$, MEDLINE ${ }^{\circ}$ and Cochrane Library were searched on the 22nd of May 2017 to capture studies reporting outcomes on absenteeism, presenteeism and productivity losses. Search terms included the following medical subject headings 'ulcerative colitis'/exp. OR 'ulcerative colitis' OR 'inflammatory bowel disease'/exp. OR 'inflammatory bowel disease' OR 'ibd' as well as cost subject headings such as 'indirect' OR 'productivity' OR 'economic' OR 'cost' OR 'loss' OR 'burden' OR 'human capital'. Additional hand searches were performed to identify studies published in important medical societies such as United European Gastroenterology Week (UEGW), European Crohn's and Colitis Organization (ECCO) and Digestive Disease Week (DDW).
For inclusion in this review, studies needed to fulfill specific criteria in accordance with a predefined $\operatorname{PICOS}^{1}$ scheme [12],

I) Population: Adult patients with a confirmed diagnosis of active ${ }^{2}$ moderate to severe UC were considered as the target population.

II) Intervention/ Comparators: No restrictions were applied to these two parameters.

III) Outcomes: indirect costs or productivity losses associated with absenteeism and/or presenteeism were considered of interest.

IV) Study type: Real Word Evidence (RWE) data, meaning observational studies, systematic literature reviews, cost estimation studies and cost effectiveness studies written in English and published between 1st of January 2006 (availability of anti-tumor necrosis factor drugs) and 22nd of May 2017 were included.

A publication was excluded if it did not fulfil the abovementioned inclusion criteria, meaning if the study did not report any kind of indirect costs or if the patient population did not have confirmed moderate to severe active UC. Randomized controlled trials, (i.e. phase 1, 2 and 3 studies), long-term extensions of clinical trials and studies with rules of protocol violation, as well as crossover trials and interventional cohort studies beyond the scope of public health interventions were excluded from this review. Publications that were not written in English were also excluded.

To assess the eligibility of a study, two authors independently examined titles and abstracts identified from the search strategy. Articles, which have been identified as potentially relevant based on title and abstract, were then reviewed in full text and selected according to the list of pre-specified inclusion/exclusion criteria. All discrepancies were solved by discussion. If no agreement was found, a third reviewer was involved in the discussion and final decision making.

As most of the studies extend across a wide time frame, all costs were converted to 2017 American dollars (\$), using country specific consumer price index from the worldwide inflation data source.

This review was conducted in accordance with the Preferred Reporting Items for Systematic Reviews and Meta-Analyses (PRISMA) statement to ensure that all records were well tracked [13].

\section{Data extraction and synthesis of literature}

Data from the eligible studies were collected, including publication details, specifications of the study question

\footnotetext{
${ }^{1}$ PICOS: Population, Intervention, Comparison, Outcome, Study type

${ }^{2}$ The authors decided to focus on active UC as its when patients experience UC like symptoms.
} 
(indication, geographical scope, intervention, comparators and study objectives), methodology used, main indirect costing results (absenteeism specifically related to sick leave as well as short/long term disability and presenteeism costs), as well as limitations associated to the study. Results were then tabulated and analyzed using descriptive statistics. Data extraction was carried out by three researchers and quality control has been done for at least $20 \%$ of extracted data, as defined in the study protocol.

In order to achieve comparability of the results across publications, we attempted to break down indirect costs into the same categories (e.g. sick leave or short- and long-term disability). We also reported cost data per patient per year and assumed that costs are stable throughout the year.

\section{Statistical analysis}

Descriptive statistics were reported for the study outcomes for all patients to describe the basic features of the data in the identified studies. Univariate, bivariate and multivariate analyses were not conducted to assess the association of baseline characteristics with cohorts nor patient characteristics with indirect costs.

\section{Results}

\section{Literature search results}

After having applied a search strategy for indirect costs in UC, 18 studies were incorporated in the narrative review, as outlined in Fig. 1. Most studies were conducted either in Europe or in the USA (12 studies in Europe, four studies in the USA, one study in Israel and one study did not report a country).

Data on indirect costs were collected from web-based questionnaire or through database analysis (17 studies), one study collected data through patient cost diaries. The majority of studies had large sample sizes, ranging from 53 to 6900 patients, as reported in Table 1.

Overall, 13 studies out of 18 studies reported data from nine different countries (mainly in Europe), on absenteeism in UC, capturing cost/loss of earning of absenteeism per patient year and/or total average indirect costs of absenteeism per patient year. With regards to presenteeism, we were only able to identify three studies, one conducted

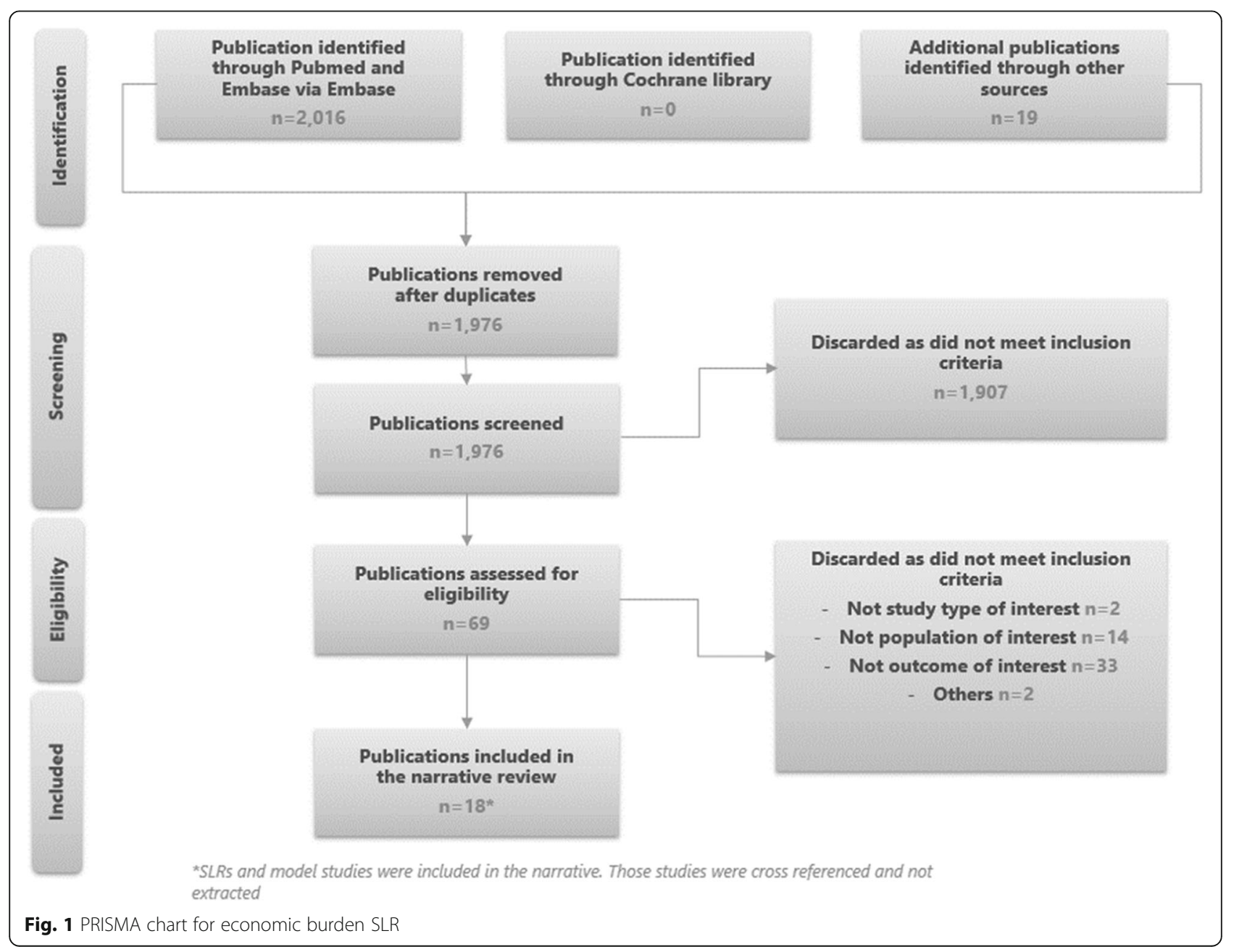


Table 1 Characteristics of identified studies

\begin{tabular}{|c|c|c|c|c|}
\hline Author, year & Country & Study population & Characteristics of study population & Follow up duration \\
\hline Kawalec et al. 2017 [14] & Poland & Patients with UC & $\begin{array}{l}N=202 \\
\text { Disease duration } 26.35 \text { years }\end{array}$ & October 2015- Q1 2016 \\
\hline Van Der Valk et al. 2016 [15] & The Netherlands & IBD patients & $\begin{array}{l}N=566 \\
\text { Disease duration } 16 \text { years }\end{array}$ & 2 years \\
\hline Malinowski et al. 2016 [16] & Poland & UC patients & $N=6900$ & NR \\
\hline Aldeguer et al. 2016 [17] & Spain & Patients with UC & $N=285$ & 12 months \\
\hline Cohen et al. 2015 [18] & USA & UC patients & $N=1728$ & $\begin{array}{l}2 \text { years ( } 1 \text { year baseline } \\
\text { period and } 1 \text { year study } \\
\text { period) }\end{array}$ \\
\hline Van Der Valk et al. 2014 [19] & The Netherlands & IBD Patients & $\begin{array}{l}N=937 \\
\text { Disease duration } 13.3 \text { years }\end{array}$ & 3 months \\
\hline Meek et al. 2013 [20] & USA & Patients with UC & $N=31,050$ & 12 months \\
\hline Cohen et al. 2012 [21] & USA & UC patients & $N=1754$ & 2 years \\
\hline Kostic et al. 2015 [22] & Serbia & Patients with UC & $N=53$ & NR \\
\hline Van Der Valk et al. 2012 [23] & The Netherlands & Patients with IBD & $N=928$ & 2 years \\
\hline Cannon et al. 2011 [24] & $N R$ & IBD patients & $N=72$ & NR \\
\hline Gibson et al. 2008 [25] & USA & Patients with $C D$ and $U C$ & $N=8970$ & NR \\
\hline Mandel M et al. 2014 [1] & Hungary & IBD patients & $\begin{array}{l}N=183 \\
\text { Disease duration } 9.9 \text { years }\end{array}$ & NR \\
\hline Katz Avitan et al. 2016 [2] & Israel & UC patients & $N=150$ & NR \\
\hline Hellström et al. 2017 [26] & Sweden & UC patients & $N=1361$ & 2 years \\
\hline Neovius et al. 2010 [27] & Sweden & UC patients & $N=2914$ & NR \\
\hline Stark et al. 2006 [28] & Germany & UC patients & $\begin{array}{l}N=483 \\
\text { Disease duration } 12 \text { years }\end{array}$ & NR \\
\hline \multirow[t]{3}{*}{ Van Der Valk et al. 2015 [29] } & \multirow[t]{3}{*}{ The Netherlands } & \multirow[t]{3}{*}{ IDB patients } & $\begin{array}{l}\text { Pouch: } n=81 \\
\text { Mean age } 46.7 \\
\text { Disease duration } 15 \text { years }\end{array}$ & \multirow[t]{3}{*}{$\begin{array}{l}\text { For } 2 \text { years at } 3 \text { months } \\
\text { intervals }\end{array}$} \\
\hline & & & $\begin{array}{l}\text { lleostomy: } n=48 \\
\text { Disease duration } 18 \text { years }\end{array}$ & \\
\hline & & & $\begin{array}{l}\text { Anti-TNFa: } n=34 \\
\text { Disease duration } 16 \text { years }\end{array}$ & \\
\hline
\end{tabular}

in Poland [14], one in Hungary [1] and one in Israel [2]. Four studies assessed total productivity loss, two in The Netherlands [15, 19], one in Serbia [22] and one in Poland [14]. Both presenteeism and productivity losses reported cost per patient year, in USD dollars converted to 2017 base year. Furthermore, treatment allocation was not clearly defined in most publications. Only one study by Van der Valk et al. [29] focused on indirect costs of antiTNF patients compared to patients who underwent surgery.

Throughout the identified studies, we noted that absenteeism costs were often classified into categories; either (1) costs associated to sick leave (Table 3), and/or (2) costs associated to short term and/or long term disability (Table 4) and/or (3) costs associated to absenteeism with no clear definition on the costing element mentioned (Table 2). These categories were analyzed independently and were reported in the sections below:

\section{Absenteeism cost}

While some publications specifically define the components associated with absenteeism, there were few publications such as Cannon et al. [24] that did not have a clear definition of absenteeism, as reported in Table 2.

The proportion of absenteeism in ulcerative colitis patients was reported in two different countries the USA and Spain. The percentage of patients experiencing absenteeism was high, even if data was limited, ranging from 85 to $98 \%$ as reported by Gibson et al. [25] and Cohen et al. [18], respectively. This can be explained by the different types of population included in both the studies. Cohen et al. [18] includes moderate to severe UC patients treated with biologics, immunosuppressant or systemic corticosteroids during the first year study period whilst Gibson et al. [25] includes all types of patients diagnosed with UC.

The average number of absenteeism days per patient year varied widely, ranging from 1.08 to 60 days per 
Table 2 Indirect costs associated with absenteeism in UC

\begin{tabular}{|c|c|c|c|c|c|c|c|}
\hline \multirow[t]{2}{*}{ Author, year } & \multirow[t]{2}{*}{ Country } & \multirow{2}{*}{$\begin{array}{l}\% \text { of patients } \\
\text { experiencing } \\
\text { absenteeism }\end{array}$} & \multirow{2}{*}{$\begin{array}{l}\text { Number of } \\
\text { days absent per } \\
\text { year/patient }\end{array}$} & \multicolumn{2}{|l|}{ Cost } & \multicolumn{2}{|l|}{ Cost adjusted } \\
\hline & & & & $\begin{array}{l}\text { Average cost } \\
\text { absenteeism } \\
\text { per patient year }\end{array}$ & $\begin{array}{l}\text { Currency, } \\
\text { base year }\end{array}$ & $\begin{array}{l}\text { Average cost } \\
\text { absenteeism } \\
\text { per patient year }\end{array}$ & $\begin{array}{l}\text { Currency, } \\
\text { base year }\end{array}$ \\
\hline Aldeguer et al. 2016 [17] & Spain & NR & 1.08 days per year ${ }^{a, b}$ & $88.21^{\mathrm{a}}$ & EURO, 2012 & 105.40 & $\$, 2017$ \\
\hline Cohen et al. 2015 [18] & USA & $98.20 \%$ & 11.5 days per year ${ }^{a}$ & 3071 & $\$, 2013$ & 3196.60 & $\$, 2017$ \\
\hline Cohen et al. 2012 [21] & USA & $N R$ & 14.2 days per year ${ }^{\mathrm{a}}$ & NR & $\$, 2010$ & NR & $\$, 2017$ \\
\hline Cannon et al. 2011 [24] & $N R^{d}$ & NR & 60 days per year ${ }^{c}$ & NR & NR & NR & NR \\
\hline Gibson et al. 2008 [25] & USA & $85.75 \%$ & NR & $6020.50^{e}$ & $\$, 2005$ & 7793.50 & \$, 2017 \\
\hline
\end{tabular}

NB: The publication by Katz Avitan et al. [2] conducted in Israel (not reported in the table) demonstrated that $21 \%$ of UC patients $(N=150)$ were experimenting absenteeism (defined as percentage of impairment while working)

${ }^{a}$ Due to medical visit specifically

${ }^{\mathrm{b}}$ In the study it was reported as $29.55 \mathrm{~h}$ per year

In the study, they reported that UC patient had missed more than 5 days from work in the past month

${ }^{\mathrm{d}}$ This publication was an abstract and did not report the country where the study was conducted

e Mean absence costs, all employees, with or without claims

patient year. The low rate of 1.08 days reported in Spain by Aldeguer et al. [17] is related to medical visits costs, where patients would be absent for a couple hours and would then return to work afterwards. Regarding the high rate of 60 days reported in Cannon et al. [24] (abstract), it was mentioned that only $9 \%$ (i.e. 7 patients) of $\mathrm{UC}$ patients experienced 60 days of absenteeism days per year. Without considering these two outliers, the range seems more stable across studies with a minimum of 11.5 of absenteeism days to a maximum of 14.2 absenteeism days per patient year in the USA.

The identified publications also report costs associated to absences from work ranging from 3197 \$ to 7794 \$ per patient year. Here again, the study by Aldeguer et al. [17] reported a lower value than the range (i.e. $105 \$$ per patient year), as seen in Table 2 .

\section{Absenteeism - sick leave}

Eight studies out of 18, all conducted in Europe, reported absenteeism costs related specifically to sick leaves in UC, as shown in Table 3. The type of patients in all these studies were pooled UC patients (i.e. with different disease states). Only Van der Valk et al. [29] looked at three types of UC patients, either treated with anti-TNFs, colectomy with J-pouch patients or colectomy with ileostomy patients. The percentage of patients experiencing sick leave was consistent across all studies and was estimated around 10 to $24 \%$. However, the number of days missed from work due to sick leaves varied greatly between publications, more specifically between 8 to 63 days per patient year. In one study conducted in the Netherlands, it was shown that patients treated with anti-TNF therapies are more likely to be absent from work (28 days per patient year), compared to patients who underwent colectomy with J-pouch (10 days per patient year) and colectomy with ileostomy (20 days per patient year). This was also reflected when looking at the cost/ loss of earning (i.e. average cost of sick leave) $4824 \$, 2147$ \$, and 1676 \$, per patient year for anti TNF, pouch and ileostomy groups, respectively. The anti-TNF group accounted for the highest absenteeism cost compared to patients who underwent pouch and ileostomy surgery.

\section{Absenteeism - short- and long-term disability}

Five $[1,16,18,25,28]$ out of 18 studies reported data on short and/or long-term disability ${ }^{3}$ in patients with UC, of which two were conducted in the USA, one in Germany, one in Hungary and one in Poland, as can be seen in Table 4. The proportion of patients experiencing short term disability was reported in three studies (USA $[18,25]$ and Germany [28]) and was consistently ranging from 15 to $17 \%$. Regarding long term disability, 7\% of UC patients experienced it, as reported by Stark et al. [28], conducted in Germany, with a total number of disability days ranging from 10 to 12 per patient year. Regarding cost data, we found that authors distinguished between short- and long-term disability costs. As expected, on average long-term disabilities were more costly than short-term disabilities, ranging from $116 \$$ to 3019 \$ per patient year for short term disability compared to the range of 1573 \$ to 4394 \$ per patient year for long term disability.

\section{Presenteeism}

Three studies estimated indirect costs associated to presenteeism, one in Poland [14], one in Hungary [1] and one in Israel [2], as indicated in Table 5.

\footnotetext{
${ }^{3}$ Short/long-term disability is defined as work cessation through job loss, early retirement, or long-term absence due to being partially or fully disabled. According to Malinowski et al. [16] short-term disability entitles a person to claim rehabilitation benefits and long-term disability entitles a person to claim disability pension.
} 


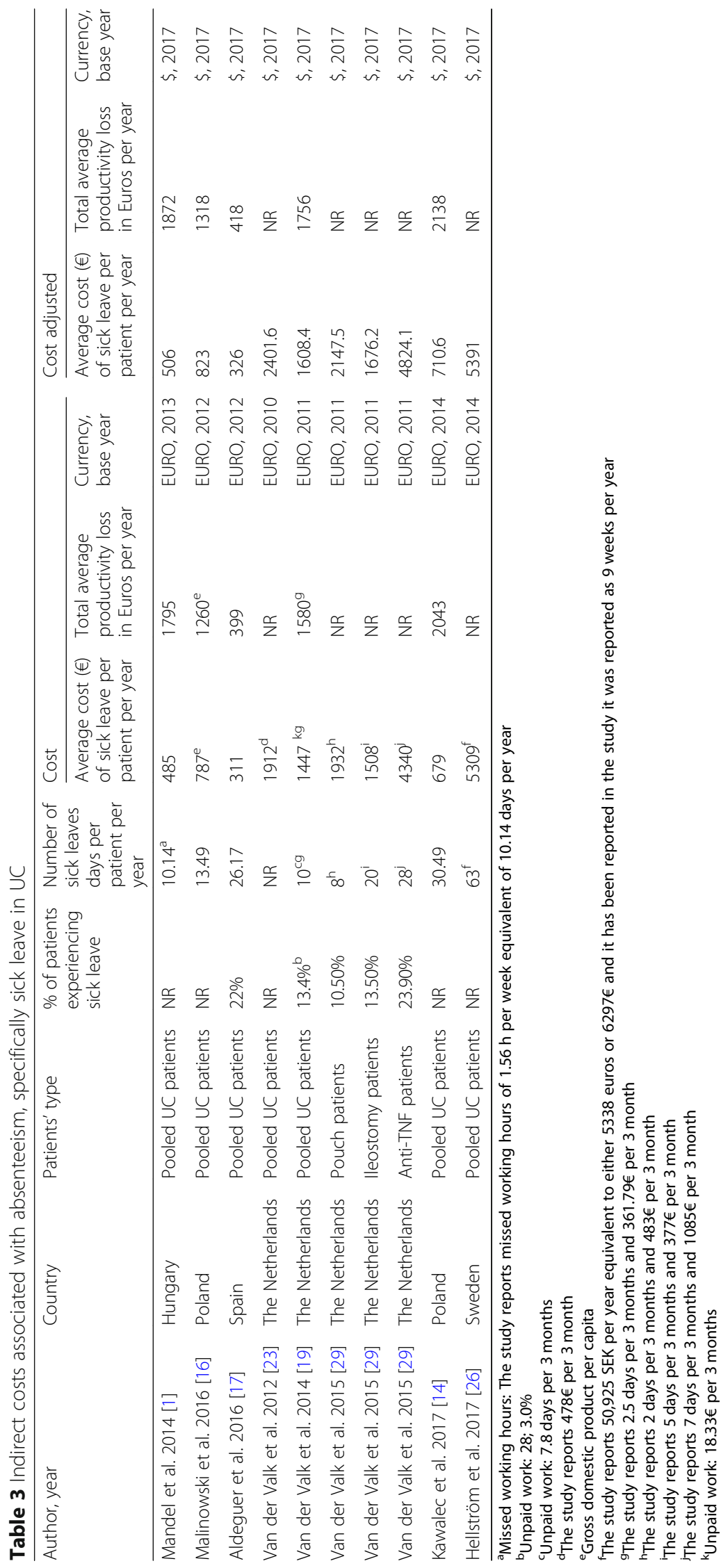




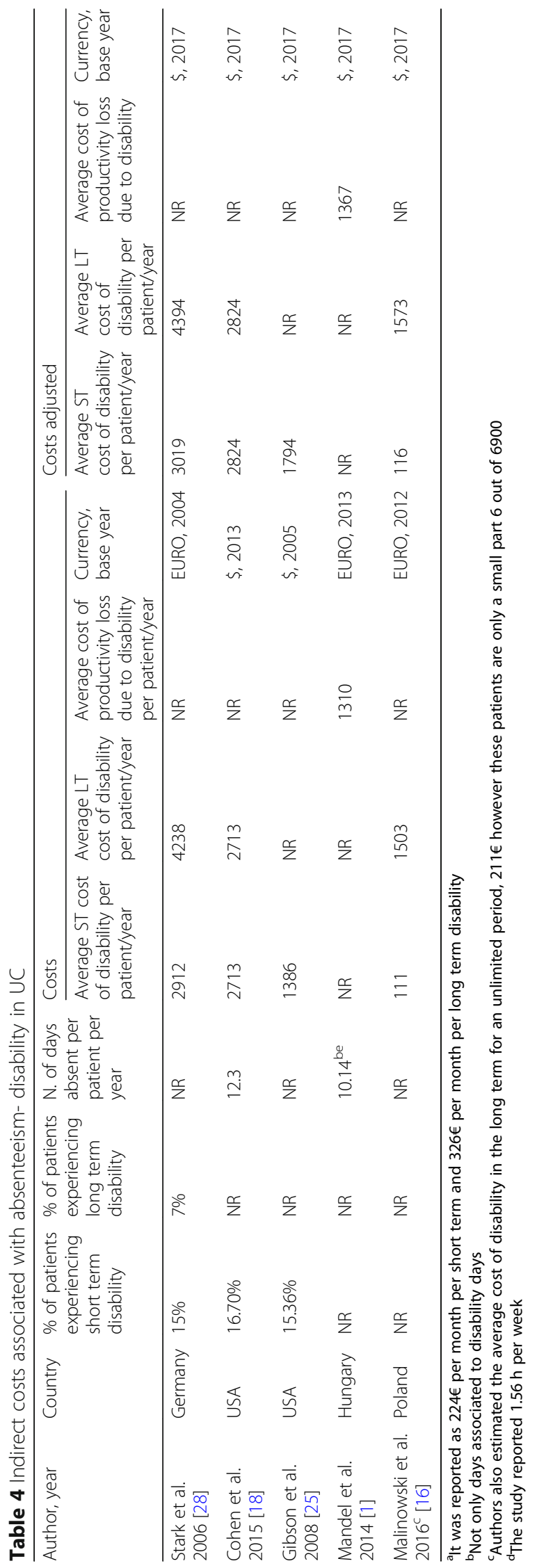


Table 5 Indirect costs associated with presenteeism in UC

\begin{tabular}{|c|c|c|c|c|c|c|c|}
\hline \multirow[t]{2}{*}{ Author, year } & \multirow[t]{2}{*}{ Country } & \multirow{2}{*}{$\begin{array}{l}\% \text { of patients } \\
\text { experiencing } \\
\text { presenteeism }\end{array}$} & \multirow{2}{*}{$\begin{array}{l}\text { On the job } \\
\text { productivity } \\
\text { loss (\%) due } \\
\text { to UC per } \\
\text { patient per } \\
\text { week }\end{array}$} & \multicolumn{2}{|l|}{ Cost } & \multicolumn{2}{|l|}{ Cost adjusted } \\
\hline & & & & $\begin{array}{l}\text { Total indirect cost } \\
\text { for presenteeism } \\
\text { per patient per year }\end{array}$ & $\begin{array}{l}\text { Currency, } \\
\text { base year }\end{array}$ & $\begin{array}{l}\text { Total indirect cost } \\
\text { for presenteeism } \\
\text { per patient per year }\end{array}$ & $\begin{array}{l}\text { Currency } \\
\text { base yea }\end{array}$ \\
\hline Kawalec et al. 2017 [14] & Poland & $55.20 \%$ & $19.38 \%$ & 1346 & EURO, 2014 & 1602.1 & $\$, 2017$ \\
\hline Mandel et al. 2014 ${ }^{\mathrm{a}}[1]$ & Hungary & NR & $19.42 \%$ & 2410 & EURO, 2013 & 2947.2 & $\$, 2017$ \\
\hline
\end{tabular}

NB: The publication by Katz Avitan et al. [2] conducted in Israel (not reported in the table) demonstrated that 19\% of UC patients $(N=150)$ experienced presesenteeism

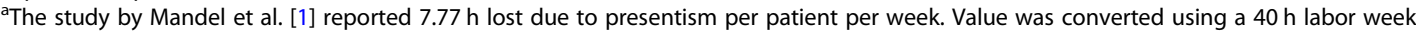

UC patients were poorly described in the publication by Kawalec et al. [14] and in Katz Avitan et al. [2], however, more information on patient characteristics was provided in Mandel et al. [1]. In fact, it was reported that $11.5 \%$ of UC patients were on biologics and $8.3 \%$ of patients had underwent colectomy.

Consistent results were found when comparing presenteeism data, as all reported that patients with UC experience a $19 \%$ job productivity loss per week, with presenteeism costs ranging from 1602 \$ to 2947 \$ per patient year.

\section{Total productivity loss}

Total productivity losses were reported in four studies, one in Poland [14], one in Serbia [22] and two in the Netherlands $[15,19]$, as shown in Table 6 . The proportion of indirect costs associated to total UC costs ${ }^{4}$ was reported in two studies, conducted in the Netherlands and by the same author. On average, indirect costs accounted for $35 \%$ of total UC costs. Furthermore, total productivity losses for high-income countries ranged from 1459 \$ in the Netherland to 2431 \$ in Poland per patient year, with costs being more expensive in Poland (2431 \$) compared to the Netherlands (2058 \$). However, in Serbia, a middle-income country, total productivity losses were lower (i.e. 1567 \$ per patient year). This difference can be explained by the under-utilization of biologic therapy and low health services prices used by IBD patients in Serbia [22].

\section{Discussion}

The chronic nature of UC as well as the way the disease evolve over time makes it a costly condition to manage. Typically, costs of hospitalizations, surgery and the management of its complications are drivers of direct medical cost. Given the disease's epidemiological characteristics and age distribution, the indirect costs due to productivity losses further contribute to high overall

${ }^{4}$ Total UC costs were defined as the sum of healthcare costs, productivity costs and out-of-pocket costs. total disease costs. The objective of this review was to understand the impact of UC on indirect costs.

Understanding and quantifying indirect costs associated to biologics versus surgery was possible through one study by Van Der Valk published in 2015 [29], that compared indirect costs in patients under anti-TNF $(n=34)$ therapies with patients who underwent surgery, either J-pouch $(n=81)$ or Ileostomy $(n=48)$. Results indicated that indirect costs were highest in patients taking anti-TNF therapies (4340€ per patient year and 28 days of sick leave per year) compared to surgical patients (with 1508 \$ per patient year and 20 days of sick leave per year for ileostomy and $1932 \$$ per patient year and 8 days of sick leave per year for pouch patients). However, little is known on the long-term cost trends of these interventions. In fact, surgery has typically been considered as a significant cost driver in UC patients, mainly due to the need for hospitalization as well as the risk for complications after the procedure. A recent review by Lindsay et al. [8] showed that, 5 years post-operation, the mean cost per patient with surgical complications was significantly greater compared to those without complications, representing 34, 714 \$ additional costs per patient. As surgical complications represent a substantial burden in terms of cost of reoperation, physician fees, additional in-patient hospital stays and infertility treatment, further studies are needed to understand the direct and indirect cost of biologics versus surgery in UC.

As healthcare systems vary greatly between countries, it was expected to identify variations in indirect costs between Europe and the USA. Giving that the majorities of identified publications reported indirect costs in Europe, it was difficult to quantify this difference. However, we noted that costs related to absenteeism were greater in the USA compared to Europe. Productivity losses were only reported in three studies. Although limited information was found, it was possible to conclude that, on average, $35 \%$ of total UC costs were associated to indirect costs. This proportion remains uncertain, as indirect costs are very difficult to assess, mainly because of difficulties in measurement, especially when talking about presenteeism (i.e. the reduction of workers' effectiveness due to illness). 
Table 6 Total productivity losses associated to UC

\begin{tabular}{|c|c|c|c|c|c|c|}
\hline \multirow[t]{2}{*}{ Author, year } & \multirow[t]{2}{*}{ Country } & \multirow{2}{*}{$\begin{array}{l}\text { Proportion } \\
\text { of indirect cost } \\
\text { associated to } \\
\text { total UC costs }\end{array}$} & \multicolumn{2}{|l|}{ Cost } & \multicolumn{2}{|l|}{ Cost adjusted } \\
\hline & & & $\begin{array}{l}\text { Total productivity losses } \\
\text { per patient year }\end{array}$ & $\begin{array}{l}\text { Currency, } \\
\text { base year }\end{array}$ & $\begin{array}{l}\text { Total productivity } \\
\text { losses per patient year }\end{array}$ & $\begin{array}{l}\text { Currency, } \\
\text { base year }\end{array}$ \\
\hline Kostic et al. 2015 [22] & Serbia & NR & 142,267 & RSD, $2015^{\mathrm{b}}$ & 1567.0 & $\$, 2017$ \\
\hline Kawalec et al. 2017 [14] & Poland & $N R$ & 2043 & EURO, 2014 & 2431.8 & \$, 2017 \\
\hline Van Der Valk, 2016 [15] & The Netherlands & $31 \%$ & 1120 & EURO, 2011 & 1459.3 & $\$, 2017$ \\
\hline Van Der Valk, 2014 [19] & The Netherlands & $39 \%$ & $1580^{\mathrm{a}}$ & EURO, 2011 & $2058.7^{\mathrm{a}}$ & $\$, 2017$ \\
\hline
\end{tabular}

${ }^{a}$ The study reports total productivity losses of $395.21 €$ per 3 months per patients

${ }^{\mathrm{b}}$ Base year was not reported. It is assumed that base year correspond to publication year

This review allowed us to conclude that costs in UC tend to be highly variable based on the subpopulation to which they refer. In fact, Cohen et al. [18] reported that in the US, patients with UC have higher direct and indirect costs compared with matched controls [18]. In fact, patients with moderate to severe UC ( $n=1728)$ had significantly $(p<0.0001)$ higher hospitalization rates $(26.5 \%$ vs $6.2 \%)$ and adjusted total direct $(23,085 \$$ vs $4932 \$)$ and indirect costs (5666 \$ vs 1960 \$) [18]. Similar conclusions were reached by Bodger et al. [30] and Hilson et al. [31] who reported significantly higher costs in severe patients compared to milder UC patients. Unfortunately, in the literature, indirect costs are poorly evaluated by UC disease state. Therefore, it remains also unclear whether these indirect costs are representative to the general UC population regardless of their disease severity/state.

This review has several limitations. No populationbased studies with control patients were included in our analysis and our findings may not be applicable to all patients with UC. After completion of our analysis, results from a prospective study was published describing data for patients with UC and CD from the Danish national registry [32]. This population-based study reported no significant difference in indirect costs between IBD (UC and $\mathrm{CD}$ ) and a control population. The authors attributed these results to a nationalized healthcare system, a high standard of treatment and a relatively young patient cohort. It was suggested that the indirect costs may increase in an older population, however this analysis was not conducted in the study [32].

Within the small number of studies that reported indirect costs in UC, heterogeneity of reporting data was a key limitation in analyzing and quantifying the impact of indirect costs in UC. Analysis was confounded by differences in costing components within the same category and across different cost categories, due to the lack of definition of these components. There remains uncertainty in the cost associated with absenteeism based on the limited information provided in the primary publications. A recent review by Kawalec et al. [14] concluded that IBD imposes a substantial personal burden and affects the ability to work, supporting our findings.
Costs were adjusted to the 2017 USD values to allow comparison between countries; however, these may not be comparable across different societies. Other limitations include: heterogeneity in the inclusion criteria (disease severity, disease history, patients' characteristics).

\section{Conclusion}

In conclusion, the findings of this review showed that indirect costs in UC are not well documented in the literature. Therefore, additional studies are needed in UC to quantify these costs per disease state and to evaluate the impact of the disease on patients' functional abilities.

\section{Abbreviations \\ DDW: Digestive Disease Week; ECCO: European Crohn's and Colitis Organization; EMA: European Medicines Agency; FDA: Food and Drug Administration; PICOS: Population, Intervention, Comparator, Outcome, Study type; PRISMA: Preferred Reporting Items for Systematic Reviews and Meta- Analyses; RWE: Real World Evidence; UC: Ulcerative colitis; UEGW: United European Gastroenterology Week; USD: United States Dollar}

\section{Acknowledgements}

Not applicable.

\section{Authors' contributions}

All authors (JC, PA, DW and AB) have made substantial contributions to the conception and design of the study, JC and PA were responsible for the acquisition of data, all authors (JC, PA, DW and $A B$ ) were responsible for the analysis and interpretation of data, JC drafted the manuscript and all authors were responsible for substantively revising it. All authors (JC, PA, DW and AB) have approved the submitted version. All authors (JC, PA, DW and AB) have agreed to be personally accountable for their individual contributions and to ensure that questions related to the accuracy or integrity of any part of the work, even ones in which the author was not personally involved, are appropriately investigated, resolved, and the resolution documented in the literature.

Funding

This study was funded by Janssen EMEA (DW and AB).

Availability of data and materials

All data generated or analyzed during this study are included in this published article.

Ethics approval and consent to participate

Not applicable.

Consent for publication

Not applicable.

Competing interests

The authors declare that they have no competing interests. 


\section{Author details}

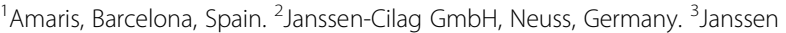
EMEA, High Wycombe, UK.

Received: 19 February 2019 Accepted: 17 October 2019

Published online: 09 November 2019

\section{References}

1. Michael MD, et al. Work disability and productivity loss in patients with inflammatory bowel diseases in Hungary in the era of biologics. Eur J Health Econ. 2014:15(1):121-8.

2. Avitan AK, Schwartz D, Greenberg D, Friger M, Vardy H, Sarid O, SlonimNevo $V$, Odes S. The impact of inflammatory bowel disease on work productivity: comparison of a real-world sample of patients with Crohn's disease and ulcerative colitis. Value Health. 2016;19(7):A511.

3. Kornbluth A, Sachar DB. Ulcerative colitis practice guidelines in adults: American college of gastroenterology, practice parameters committee. Am J Gastroenterol. 2010;105(3):501-23.

4. Danese S, Fiocchi C. Medical progress in ulcerative colitis-review article. N Engl J Med. 2011;365:1713-25.

5. Allen PB, Lindsay $H$, Tham TC. How do patients with inflammatory bowel disease want their biological therapy administered? BMC Gastroenterol. 2010;10(1):1

6. REMICADE ${ }^{\oplus}$ (infliximab) is first biologic approved in European Union to treat ulcerative colitis. Evaluate, Editor. 2006. https://www.ptcommunity.com/ news/20060309/remicade-approval-marks-first-biologic-therapy-treatulcerative-colitis-european-union.

7. Cohen $\mathrm{R}$, et al. Systematic review: the costs of ulcerative colitis in Western countries. Aliment Pharmacol Ther. 2010;31(7):693-707.

8. Lindsay J, et al. Systematic review: the financial burden of surgical complications in patients with ulcerative colitis. Aliment Pharmacol Ther. 2015:41(11):1066-78.

9. Annemans $L$, Aristides $M$, Kubin M. Real-life data: a growing need. ISPOR Connections. 2007;13(5):8-12

10. Kawalec P. Indirect costs of inflammatory bowel diseases: Crohn's disease and ulcerative colitis. A systematic review. Arch Med Sci. 2016;12(2):295.

11. Nguyen GC, Tuskey A, Dassopoulos T, Harris ML, Brant SR. Rising hospitalization rates for inflammatory bowel disease in the United States between 1998 and 2004. Inflamm Bowel Dis. 2007;13(12):1529-35.

12. Thompson, M., et al., A framework to facilitate the use of systematic reviews and meta-analyses in the design of primary research studies. 2012.

13. Moher D, et al. Preferred reporting items for systematic reviews and metaanalyses: the PRISMA statement. PLoS Med. 2009:6(7):e1000097.

14. Kawalec $P$, et al. Disease activity, quality of life, and indirect costs of ulcerative colitis in Poland. Prz Gastroenterol. 2017;12(1):60

15. van der Valk ME, et al. Evolution of costs of inflammatory bowel disease over two years of follow-up. PLoS One. 2016;11(4):e0142481.

16. Malinowski KP, Kawalec PP, Moćko P. Indirect costs of absenteeism due to rheumatoid arthritis, psoriasis, multiple sclerosis, insulin-dependent diabetes mellitus, and ulcerative colitis in 2012: a study based on real-life data from the social insurance institution in Poland. Expert Rev Pharmacoecon Outcomes Res. 2016;16(2):295-303.

17. Aldeguer $X$, Sicras-Mainar A. Costs of ulcerative colitis from a societal perspective in a regional health care area in Spain: a database study. Gastroenterol Hepatol (English Edition). 2016;39(1):9-19.

18. Cohen $\mathrm{R}$, et al. Direct and indirect healthcare resource utilization and costs associated with ulcerative colitis in a privately-insured employed population in the US. J Med Econ. 2015;18(6):447-56.

19. Van Der Valk ME, et al. Healthcare costs of inflammatory bowel disease have shifted from hospitalisation and surgery towards anti-TNFa therapy: results from the COIN study. Gut. 2014;63(1):72-9.

20. Meek PD, et al. Tu1112 direct and indirect cost burden of ulcerative colitis: a matched analysis of healthcare costs, absenteeism, and short term disability costs in US patients with and without ulcerative colitis. Gastroenterology. 2013;144(5):S-765

21. Cohen. Direct and indirect utilization and costs associated with ulcerative colitis; 2012.

22. Kostic M, et al. Costs of Inflamatory bowel disease (Crohns disease and ulcerative colitis) in Serbia. Value Health. 2015;18(7):A624.
23. Van der Valk M, et al. OP09 Anti TNF-a therapy is a major cost driver in inflammatory bowel disease: Results from the COIN study. J Crohns Colitis. 2012;6(Supplement_1):S5.

24. Cannon MD, et al. The individual financial burden of inflammatory bowel disease; the economic colitis. Gastroenterology. 2011;140(5):S-202.

25. Gibson TB, et al. The direct and indirect cost burden of Crohn's disease and ulcerative colitis. J Occup Environ Med. 2008;50(11):1261-72.

26. Hellström PM, Stålhammar J, Beydogan, Huetson, Skup M, Agréus. Indirect burden of patients with moderate inflammatory bowel disease in Uppsala County Council, Sweden: a retrospective study using real-world data; 2017

27. M. Neovius, E.A. P. Blomqvist, Fredrik Granath, Anders Ekbom, K. Ekstrom Smedby. Sick leave and disability pension in the Swedish ulcerative colitis population: nationwide cohort study. 2011.

28. Stark R, König H-H, Leidl R. Costs of inflammatory bowel disease in Germany. Pharmacoeconomics. 2006;24(8):797-814.

29. van der Valk ME, et al. Comparison of costs and quality of life in ulcerative colitis patients with an ileal pouch-anal anastomosis, ileostomy and antiTNFa therapy. J Crohn's Colitis. 2015;9(11):1016-23.

30. Bodger $\mathrm{K}$, et al. Medical resource utilization and associated costs in patients with ulcerative colitis in the UK: a chart review analysis. Eur J Gastroenterol Hepatol. 2014;26(2):213-21.

31. Hillson $E_{\text {, et }}$ al. Health care expenditures in ulcerative colitis: the perspective of a self-insured employer. J Occup Environ Med. 2008;50(8):969-77.

32. Lo, B., et al., Direct and indirect costs of inflammatory bowel disease: ten years of follow up in a Danish population-based inception cohort. 2019.

\section{Publisher's Note}

Springer Nature remains neutral with regard to jurisdictional claims in published maps and institutional affiliations.
Ready to submit your research? Choose BMC and benefit from:

- fast, convenient online submission

- thorough peer review by experienced researchers in your field

- rapid publication on acceptance

- support for research data, including large and complex data types

- gold Open Access which fosters wider collaboration and increased citations

- maximum visibility for your research: over $100 \mathrm{M}$ website views per year

At BMC, research is always in progress.

Learn more biomedcentral.com/submissions 